\title{
Initiating a New Era of Cardiovascular Diagnosis and Therapy in Acute Aortic Syndromes: The Mainz-Essen Experience (Part I)-Imaging and Biomarkers
}

\author{
Eduardo Bossone, MD, PhD ${ }^{1, *(1)}$ Riccardo Gorla, MD, PhD ${ }^{2, *(1)}$ Brigida Ranieri, $\mathrm{PhD}^{3(0)}$ \\ Valentina Russo, MD ${ }^{4}$ Heinz Jakob, $\mathrm{MD}^{5}$ Raimund Erbel, MD, MBA ${ }^{6}$
}

${ }^{1}$ Division of Cardiology, A. Cardarelli Hospital, Naples, Italy

2 Division of Cardiology, Scientific Institute for Research,

Hospitalization and Healthcare Policlinico San Donato, San Donato Milanese, Milan, Italy

${ }^{3}$ Department of Imaging, Scientific Institute for Research,

Hospitalization and Healthcare SDN, Naples, Italy

4 Department of Advanced Biomedical Sciences, Federico II University

of Naples, Naples, Italy

${ }^{5}$ Department of Thoracic and Cardiovascular Surgery, West German

Heart and Vascular Center, University of Duisburg-Essen, University

Hospital Essen, Essen, Germany

${ }^{6}$ Institute for Medical Informatics, Biometry and Epidemiology

(IMIBE), University of Duisburg-Essen, University Hospital Essen,

Essen, Germany

Aorta (Stamford) 2021;9:127-138

\begin{abstract}
Address for correspondence Eduardo Bossone, MD, PhD, Cardiology Division, A. Cardarelli Hospital, Via A. Cardarelli, 9-80131 Naples, Italy (e-mail: eduardo.bossone@aocardarelli.it).
\end{abstract}

\begin{abstract}
Keywords

- acute aortic syndromes

- Mainz-Essen

- acute aortic dissection

- hybrid operating room

- heart team concept

Acute aortic syndromes (AAS) encompass a group of life-threatening medical conditions (acute aortic dissection [AAD], intramural hematoma, and penetrating aortic ulcer) with a common pathophysiological pathway. Due to overlapping symptoms and signs with other cardiovascular emergencies, the diagnosis remains challenging resulting in time delays and related increased in-hospital and long-term morbidity and mortality. The Cardiovascular Department of Johannes Gutenberg University in Mainz at West-German Heart Centre in Essen (Germany) first described (in 1984) AAD by transesophageal echocardiography, AAD diagnostic features, and furtherly explored the implementation of "invasive" imaging techniques, namely, intravascular ultrasound and intraluminal phased-array imaging. Furthermore, pioneer studies were undertaken on the biomarker and imaging interplay, namely, D-dimer and F-fluorodeoxyglucose positron emission tomography/computed tomography. We discuss the unique 35-year-long Mainz-Essen experience on the diagnostic and prognostic role of serological and imaging biomarkers in AAS.
\end{abstract}

\section{Introduction}

Acute aortic syndromes (AAS) encompass a group of lifethreatening medical conditions with a common pathophysio-

\footnotetext{
* Equally contributed.
}

received

June 5,2020

accepted after revision

February 25, 2021

published online

November 8, 2021
DOI https://doi.org/

$10.1055 / \mathrm{s}-0041-1730295$.

ISSN 2325-4637. logical pathway (i.e., breakdown of intima and media) that leads to different clinical scenarios, including acute aortic dissection (AAD), intramural hematoma (IMH), penetrating aortic ulcer (PAU), and traumatic aortic injury (- Tables 1 and 2). ${ }^{1-8}$

Due to overlapping symptoms and signs with other cardiovascular emergencies (namely, acute coronary syndromes, (c) 2021. The Author(s).

This is an open access article published by Thieme under the terms of the Creative Commons Attribution License, permitting unrestricted use, distribution, and reproduction so long as the original work is properly cited. (https://creativecommons.org/licenses/by/4.0/)

Thieme Medical Publishers, Inc., 333 Seventh Avenue, 18th Floor, New York, NY 10001, USA 
Table 1 Acute aortic syndromes: definition and incidence

\begin{tabular}{|c|c|c|c|}
\hline AAS & Definition $^{1}$ & Incidence $^{a}$ & Remarks $^{1}$ \\
\hline $\begin{array}{l}\text { Aortic } \\
\text { dissection } \\
(85-95 \%)\end{array}$ & $\begin{array}{l}\text { Disruption of the medial layer provoked by } \\
\text { intramural bleeding, resulting in separation of } \\
\text { the aortic wall layers and subsequent formation } \\
\text { of a true lumen and a false lumen (FL) with or } \\
\text { without communication }\end{array}$ & $2.6-6^{2-4}$ & $\begin{array}{l}\text { - The real incidence is difficult to define due to } \\
\text { pre-hospital mortality and/or missing diag- } \\
\text { nosis } \\
\text { - The incidence is higher in men and increases } \\
\text { with age. } \\
\text { - Types: } \\
\text { 67\% Type A } \\
\text { 33\% Type B }\end{array}$ \\
\hline $\begin{array}{l}\text { Intramural } \\
\text { hematoma } \\
(10-25 \%)\end{array}$ & $\begin{array}{l}\text { Presence of hematoma in the media of the } \\
\text { aortic wall in the absence of an FL and intimal } \\
\text { tear }\end{array}$ & $\sim 1.2^{2}$ & $\begin{array}{l}\text { - Mainly in older patients } \\
\text { - Types: } \\
\text { 10-30\% Type A } \\
60-70 \% \text { Type B } \\
\text { - } 30-40 \% \text { of Type A IMH evolved into AD }\end{array}$ \\
\hline $\begin{array}{l}\text { Penetrating } \\
\text { aortic ulcer } \\
(2-7 \%)\end{array}$ & $\begin{array}{l}\text { Ulceration of an aortic atherosclerotic plaque } \\
\text { penetrating through the internal elastic lamina } \\
\text { into the media }\end{array}$ & $\sim 2.1^{2}$ & $\begin{array}{l}\text { - Often multiple and different in size and depth. } \\
\text { - More frequent in older age, male gender and } \\
\text { in patients with atherosclerotic cardiovascular } \\
\text { disease. } \\
\text { - Types }{ }^{6} \text { : } \\
\text { Rare in ascending aorta } \\
\sim 17.5 \% \text { aortic arch } \\
\sim 68 \% \text { descending aorta } \\
\sim 14 \% \text { thoracoabdominal transition }\end{array}$ \\
\hline
\end{tabular}

Abbreviation: AAS, acute aortic syndromes.

Note: Data from references. ${ }^{1-6}$

${ }^{\mathrm{a} A l l}$ data are per 100,000 person-years.

Table 2 Classification systems of acute aortic syndromes ${ }^{1}$

\begin{tabular}{|c|c|c|}
\hline Classification & Types/Categories & Description \\
\hline \multirow[t]{2}{*}{ Stanford } & Type A & All dissections involving the ascending aorta irrespective of the site of tear \\
\hline & Type B & $\begin{array}{l}\text { All dissections that do not involve the ascending aorta; note that } \\
\text { involvement of the aortic arch without involvement of the ascending } \\
\text { aorta in the Stanford classification is labeled as Type B }\end{array}$ \\
\hline \multirow[t]{5}{*}{ DeBakey } & Category I & $\begin{array}{l}\text { Dissection tear in the ascending aorta propagating distally to include } \\
\text { at least the aortic arch and typically the descending aorta }\end{array}$ \\
\hline & Category II & Dissection tear only in the ascending aorta \\
\hline & Category III & Dissection tear in the descending aorta propagating most often distally \\
\hline & Category IIla & Dissection tear only in the descending thoracic aorta \\
\hline & Category IIIb & Tear extending below the diaphragm \\
\hline \multirow[t]{5}{*}{ Svensson } & Class I & Classical dissection with true and false lumen \\
\hline & Class II & Intramural hematoma or hemorrhage \\
\hline & Class III & Subtle dissection without hematoma \\
\hline & Class IV & Penetrating atherosclerotic aortic ulcer \\
\hline & Class V & latrogenic or traumatic dissection \\
\hline \multirow{3}{*}{$\begin{array}{l}\text { Time course: from } \\
\text { symptom onset to } \\
\text { presentation } \\
\text { Erbel et al }\end{array}$} & Acute & $<14$ days \\
\hline & Subacute & 15-90 days \\
\hline & Chronic & $>90$ days \\
\hline
\end{tabular}

Note: Modified from references. $1,7,8$

pulmonary embolism, and stroke), the diagnosis remains challenging resulting in time delays and related increased in-hospital and long-term morbidity and mortality. Thus, a high clinical index of suspicion is needed from the caring physician (team) to make a timely diagnosis and proceed to the appropriate diagnostic tests (biomarkers and imaging) and therapeutic interventions. During the last decades, clinical and laboratory (biomarkers and genetic) and imaging data derived by single centers, as well as multiple registries and populationbased studies along with consensus statements/guidelines, 
developed by American and European Specialty Societies, have provided key insights for designing optimal diagnostic and therapeutic pathways. ${ }^{1,9}$ In Europe, the Cardiovascular Department of Johannes Gutenberg University in Mainz, Germany, first described AAD by transesophageal echocardiography (TEE) in $1984^{10}$ and furtherly investigated the role of invasive imaging (mainly TEE and intravascular ultrasound [IVUS]) versus computed tomography (CT) to rapidly confirm AAS without delaying treatment. Furthermore, pioneer studies were undertaken on the diagnostic and prognostic role of biomarker and imaging interplay, namely, D-dimer and F-fluorodeoxyglucose (FDG) positron emission tomography (PET)/CT. Twenty years later, the West-German Heart Centre in Essen, Germany, developed the concept of "hybrid operating room (HOR)" and established it in 2003 aiming at an integrated invasive diagnostic assessment and treatment in AAS patients, and becoming, over years, a center of excellence with great expertise in this field. We report and discus this unique 35-year-long Mainz-Essen experience in the field of diagnosis (part I) and management (part II) of AAS (-Tables 3 and 4; Supplementary Box 51, including - Supplementary Fig. $\mathbf{S 1}$ [available in the online version]). ${ }^{11-30}$

\section{Role of Different Imaging Modalities in Acute Aortic Syndromes}

Diagnostic imaging represents an essential step in the diagnostic and prognostic pathways of AAS. In the emergency scenario, $\mathrm{CT}$ is the most commonly used imaging modality (first choice in two-thirds of patients) followed by TEE. Magnetic resonance imaging (MRI) for its intrinsic characteristics is much less implemented being more suitable for follow-up. Being invasive, retrograde aortography (historic gold standard) is performed only when coronary angiography and/or endovascular interventions are planned. Each patient usually undergoes more than one imaging modality before definitive diagnosis is made and any appropriate treatment is undertaken. - Table $\mathbf{5}$ describes the diagnostic value, advantages, and disadvantages of each technique. ${ }^{1}$

\section{Transthoracic/Transesophageal Echocardiography}

Transthoracic echocardiography (TTE) is routinely used in the emergency scenario for differential diagnosis of many cardiologic conditions. In fact, it rapidly detects dissectionrelated complications, such as pericardial effusion with or without hemodynamic compromise, aortic regurgitation, and global or regional wall motion abnormalities, suggesting heart failure and/or acute coronary syndrome, respectively. However, while TTE allows accurate assessment of the aortic valve and ascending aorta, it often fails to comprehensively visualize the aortic arch and descending aorta (overall low accuracy). Furthermore, it is limited in presence of particular chest configuration, obesity, and pulmonary emphysema. On the other hand, TEE provided prompt availability and local expertise and can be performed to accurately evaluate patients with known or suspected AAS at bedside and/or in the operating room without the need for radiocontrast agents. Reverberation artifacts, suboptimal resolution for the distal ascending aorta/proximal aortic arch (TEE "blind spot" due to tracheal air shadowing), as well as for the abdominal aorta (distance from the imaging probe), underscore the need for a second imaging test (CT in the large majority of cases) in some patients. In addition, contraindications to TEE, such as esophageal disease and cervical spine disorders, should also be considered. Finally, TEE is less suited than CT and MRI for long-term imaging surveillance which requires a comprehensive assessment of the aorta and its branch vessels at easily identifiable landmarks. Another advantage is that serial measurements with high spatial orientation are easily possible.

\section{Transesophageal Echocardiography Studies}

The first description of AAD by TEE was reported by Börner et $\mathrm{al}^{10}$ in 1984 (- Fig. 1). It took many years to convince that TEE is the method of choice in the acute setting, to show that it is safe and very accurate so that therapeutic decision-making is possible, and can be a new field for cardiologists during that time. Subsequently, in 1987, the accuracy of TEE for the diagnosis of AAD was compared with TTE, CT, and aortography in 21 patients undergoing TEE, confirming AAD diagnosis in all 21 patients examined. TTE accuracy was significantly higher in DeBakey Type I and II, compared with Type-III AAD, but this limitation could be overcome by TEE. In all patients, TEE was able to visualize the entire descending aorta, part of the aortic arch (due to interposition of trachea) and aortic root; additionally, it could identify, in all cases, the entry tear of intimal flap as compared with $\mathrm{CT}$. ${ }^{11}$

Already in this study, the authors pointed out a very important drawback, the ultrasound artifacts suggesting an aortic intimal flap due to a reverberation of the sound waves. verified by intraoperative controls in aortic aneurysms. ${ }^{11}$ Furthermore, TEE could visualize underlying aorta and aortic valve morphologies predisposing to $A A D$, thus guiding additional treatment on the aortic valve complex. A new window to the heart was opened. ${ }^{31}$

In a first European multicenter study, the accuracy of TTE/ TEE was compared with CT (at that time only single detector systems) and aortography (MRI not yet available for emergency cases). TTE/TEE showed an excellent sensitivity and specificity (99 and 98\%, respectively) with optimal positive and negative predictive value (98 and 99\%, respectively), as compared with that of CT ( 83 and $100 \%$, respectively, with positive and negative predictive values of 100 and 86\%). In contrast, aortography showed a lower sensitivity (88\%), specificity (94\%), positive (96\%), and negative (84\%) predictive values but was crucial for identifying branch vessel involvement by dissection flap. ${ }^{12}$ Characterization of AAD morphology and entry localization by TEE had also important prognostic implications. Patients with Type-III AAD with retrograde propagation of dissection to the ascending aorta represent a subgroup with poor prognosis, similarly to patients with high communicating AAD, as free communication between the true and false lumen (TL and FL, respectively) and high flow rates are associated with high pressure and wall stress in FL.

On the other hand, thrombus formation in the FL was a good prognostic factor; notably, signs of aortic rupture (mediastinal hematoma and pericardial and pleural effusion) could be 


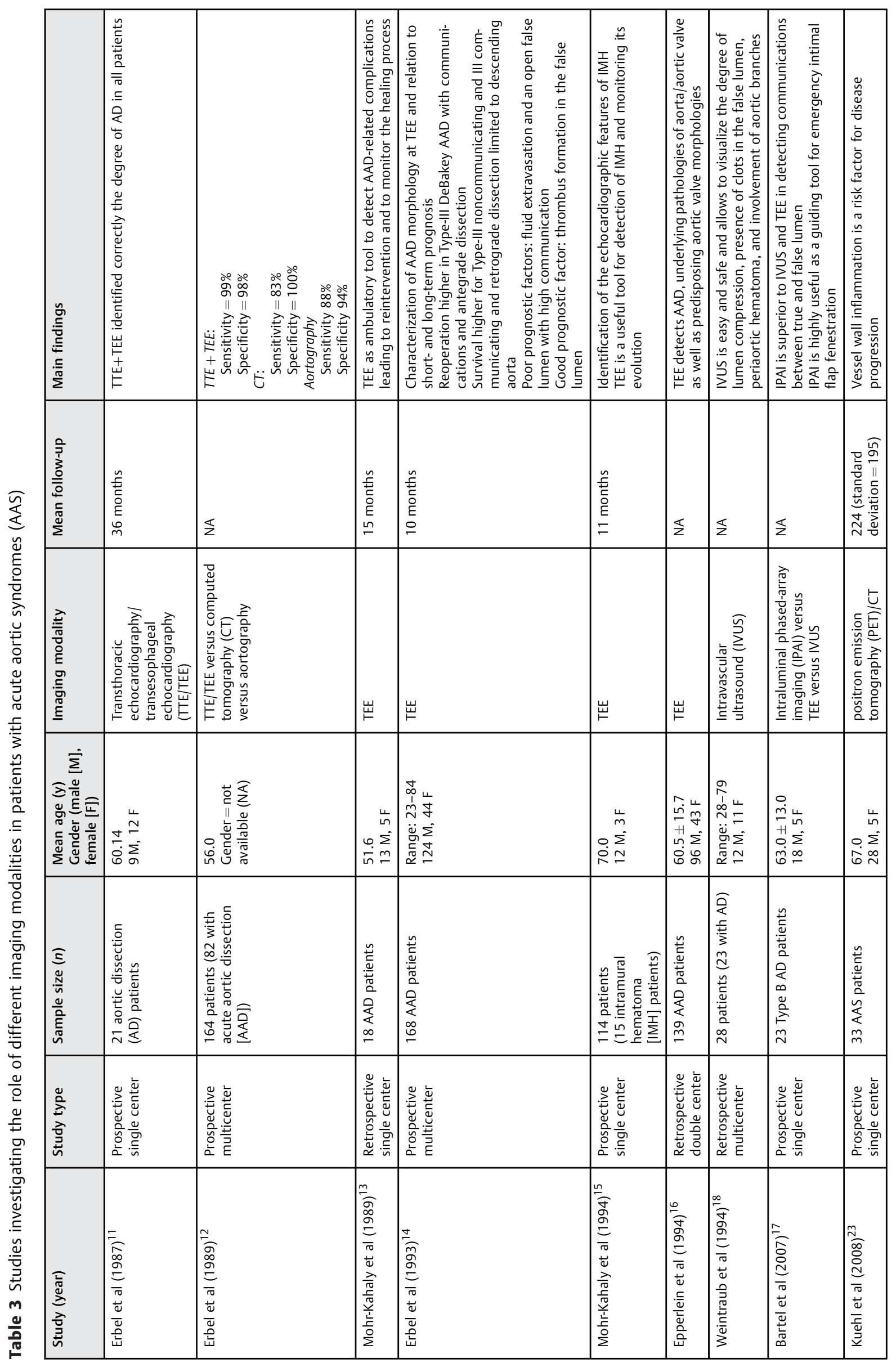




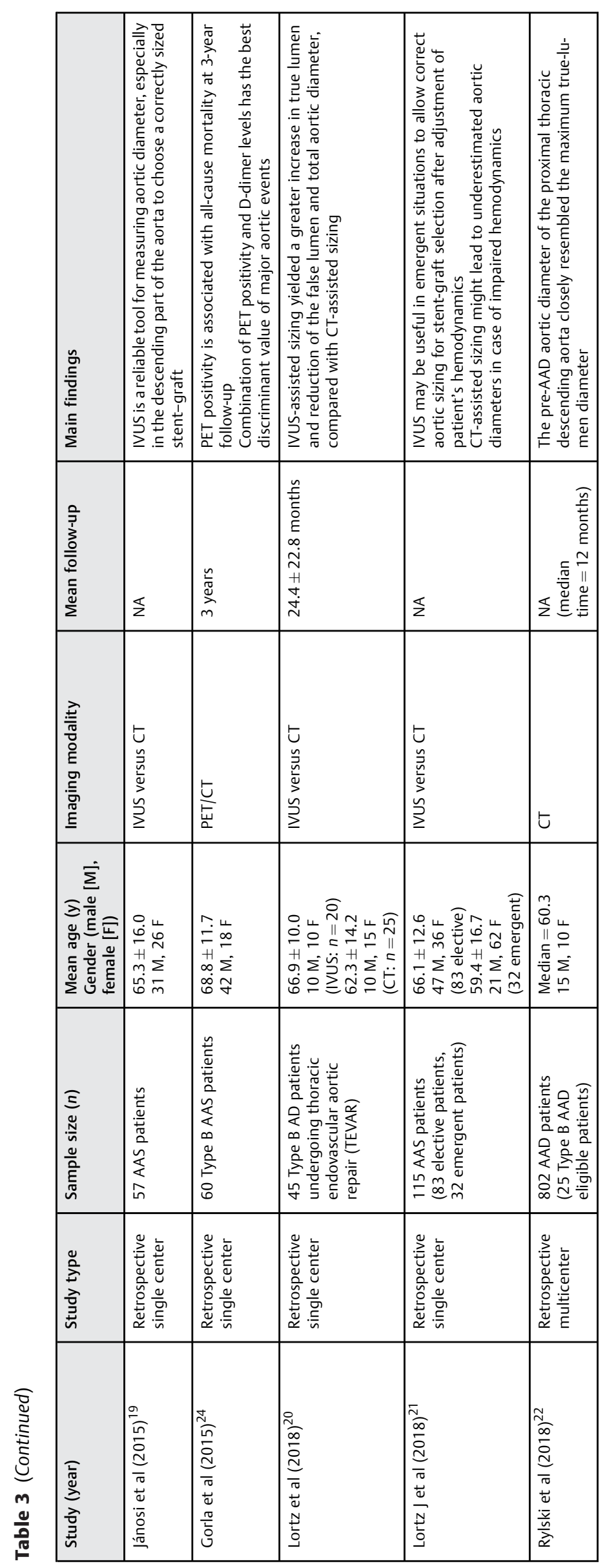




\begin{tabular}{|c|c|c|c|c|c|c|}
\hline 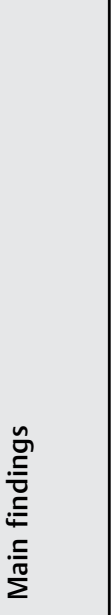 & 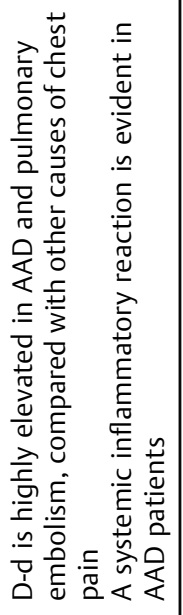 & 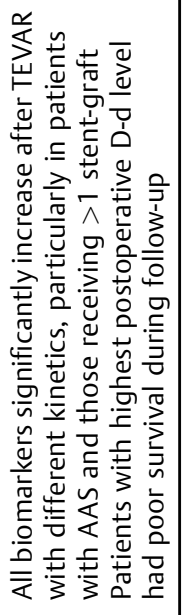 & 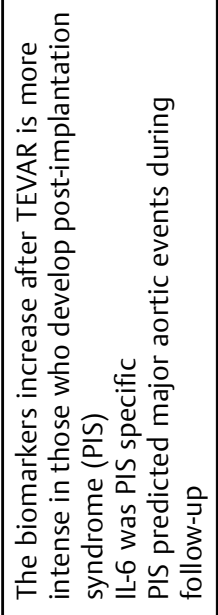 & 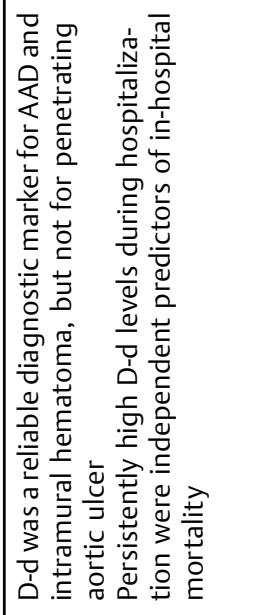 & 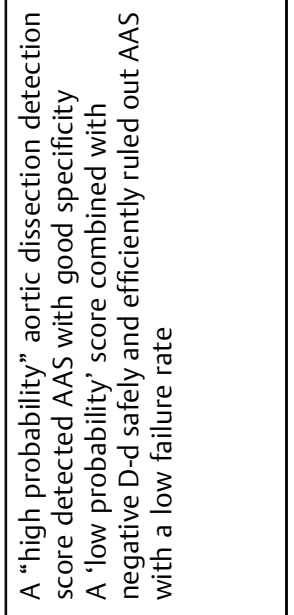 & 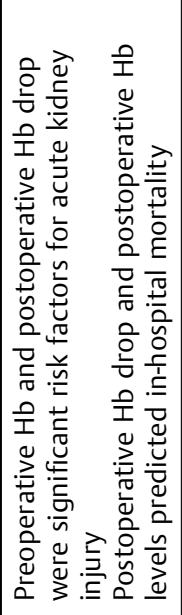 \\
\hline 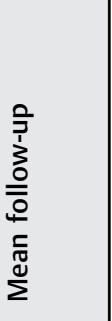 & 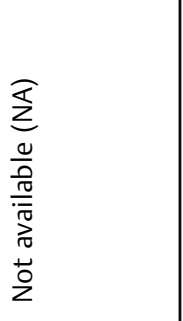 & 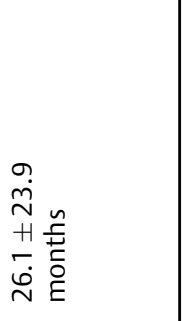 & 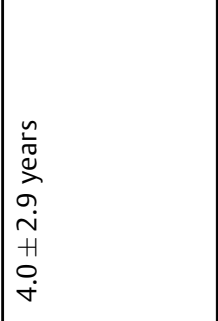 & 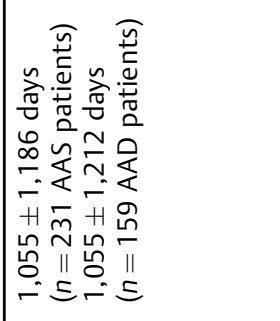 & $\Sigma$ & 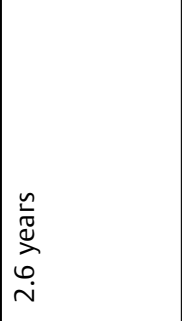 \\
\hline 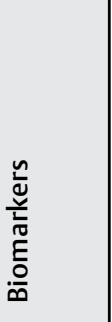 & 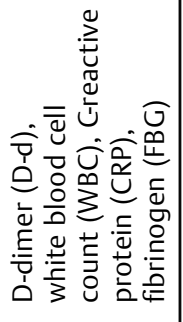 & 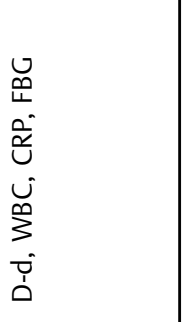 & 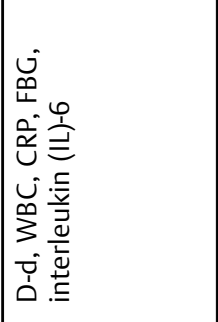 & í & í & 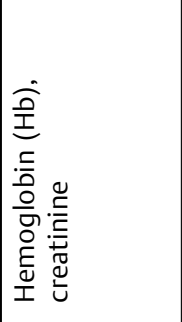 \\
\hline 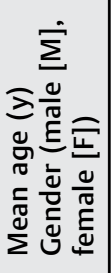 & 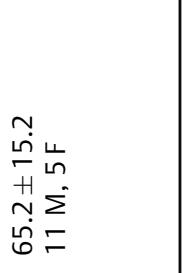 & 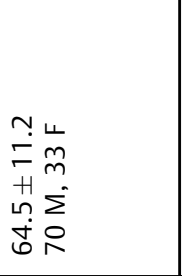 & 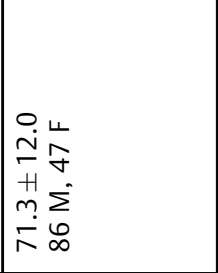 & 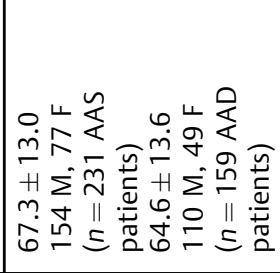 & 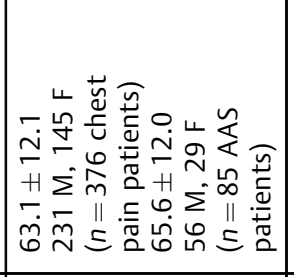 & 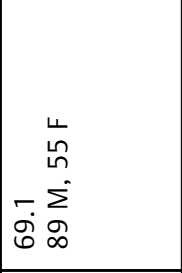 \\
\hline 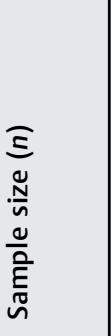 & 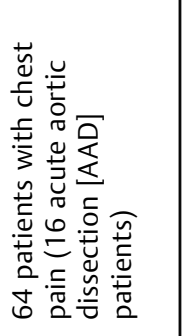 & 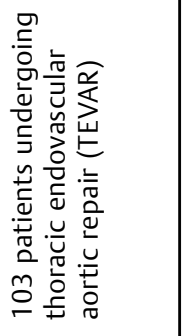 & 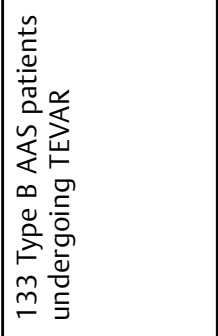 & 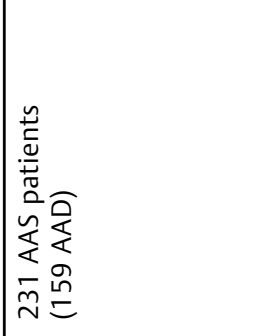 & 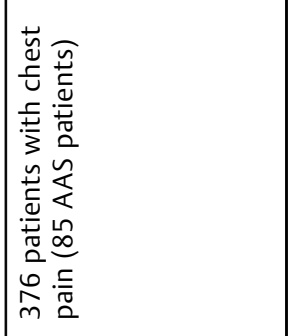 & 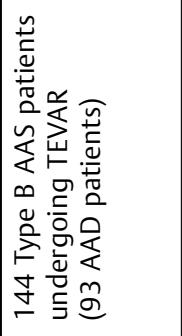 \\
\hline 离 & 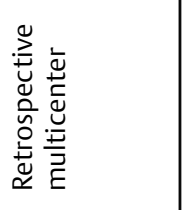 & 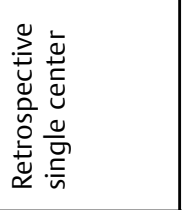 & 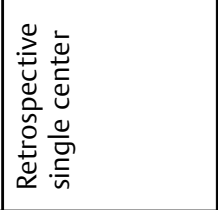 & 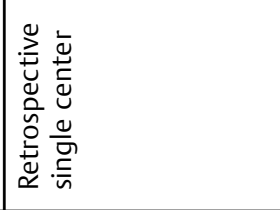 & 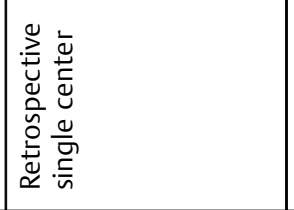 & 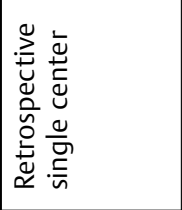 \\
\hline 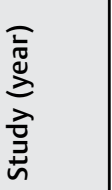 & 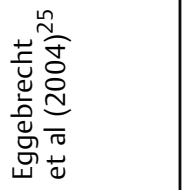 & 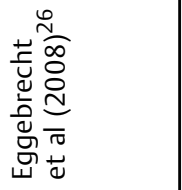 & 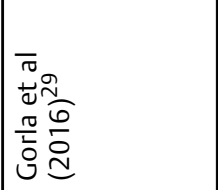 & 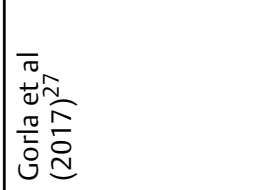 & 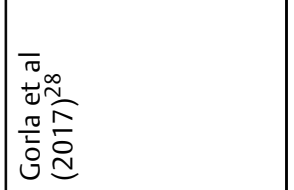 & 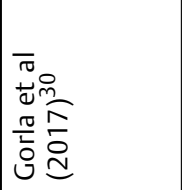 \\
\hline
\end{tabular}


Table 5 Diagnostic value and advantages/disadvantages of imaging modalities for acute aortic syndromes

\begin{tabular}{|c|c|c|c|c|}
\hline $\begin{array}{l}\text { Diagnostic value/Advantages/ } \\
\text { Disadvantages }\end{array}$ & $\begin{array}{l}\text { Transthoracic } \\
\text { echocardiography }\end{array}$ & $\begin{array}{l}\text { Transesophageal } \\
\text { echocardiography }\end{array}$ & $\begin{array}{l}\text { Computed } \\
\text { tomography }\end{array}$ & $\begin{array}{l}\text { Magnetic } \\
\text { resonance imaging }\end{array}$ \\
\hline \multicolumn{5}{|l|}{ Diagnostic value: } \\
\hline Ascending aortic dissection & ++ & +++ & +++ & +++ \\
\hline Aortic arch dissection & + & + & +++ & +++ \\
\hline Descending aortic dissection & + & +++ & +++ & +++ \\
\hline Size & ++ & +++ & +++ & +++ \\
\hline Mural thrombus & + & +++ & +++ & +++ \\
\hline Intramural hematoma & + & +++ & ++ & +++ \\
\hline Penetrating aortic ulcer & ++ & ++ & +++ & +++ \\
\hline Involvement of aortic branches & $+^{\mathrm{a}}$ & $(+)$ & +++ & +++ \\
\hline Aortic wall visualization $^{\mathrm{b}}$ & + & +++ & +++ & +++ \\
\hline Comprehensive aortic assessment & + & ++ & +++ & +++ \\
\hline Functional data & +++ & +++ & ++ & +++ \\
\hline Overall diagnostic reliability & + & $++(+)$ & +++ & +++ \\
\hline \multicolumn{5}{|l|}{ Advantages/disadvantages: } \\
\hline Ease of use & +++ & ++ & +++ & ++ \\
\hline Portability & +++ & +++ & - & - \\
\hline Rapidity & +++ & ++ & +++ & + \\
\hline Performed at bedside & +++ & +++ & - & - \\
\hline Serial examinations & ++ & + & $++(+)^{c}$ & +++ \\
\hline Cost & - & - & -- & $-\cdots$ \\
\hline Radiation & 0 & 0 & --- & 0 \\
\hline Nephrotoxicity & 0 & 0 & --- & - \\
\hline Need of sedation & - & +++ & - & - \\
\hline
\end{tabular}

Notes: Modified from Erbel et al. ${ }^{1}$

${ }^{+}$means a positive remark and - means a negative remark. The number of signs indicates the estimated potential value.

${ }^{a}$ Can be improved when combined with vascular ultrasound (carotid, subclavian, vertebral, celiac, mesenteric and renal arteries).

DPET can be used to visualize suspected aortic inflammatory disease.

$c_{+}++$only for follow-up after aortic stenting (metallic struts), otherwise limit radiation.

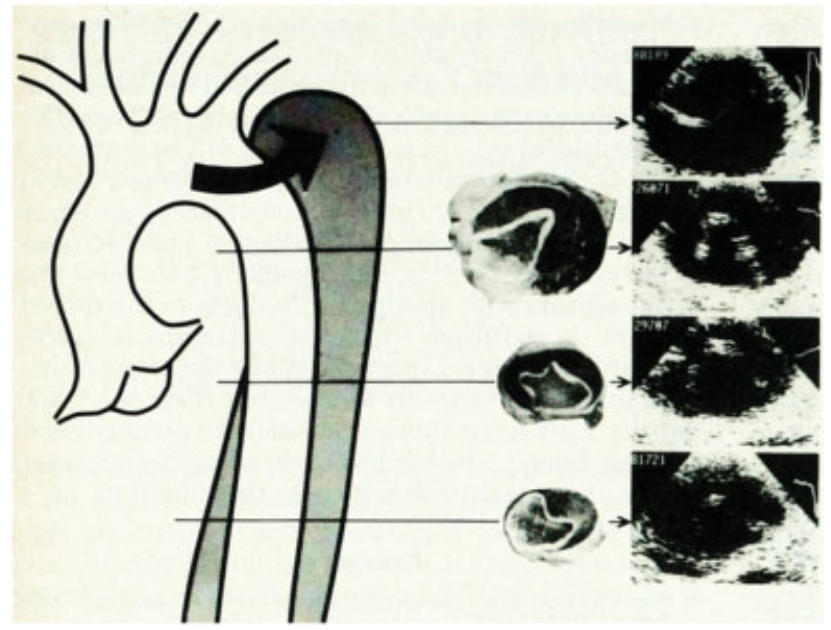

Fig. 1 Anatomopathological sections and sonographic cross-sectional scans of the dissected descending thoracic aorta (Type III dissection), which revealed the similarity between transesophageal echocardiography and autopsy. Image courtesy: Börner at al. ${ }^{10}$ visualized by TEE with high sensitivity and were associated with high mortality, independently of AAD type (51-75\%). ${ }^{32}$ Furthermore, TEE can provide information on flow dynamics between TL and $\mathrm{FL}$ in $\mathrm{AAD}$ patients over time. In a follow-up study involving 18 AAD patients, TEE was able to detect additional intimal tears which were not evident during the index TEE, as well as to distinguish between a biphasic flow from TL to FL with diastolic flow reversal (associated with large tears and no or localized thrombus), and a slowly circulating flow pattern (associated with small tears and extensive or progressive from distal to proximal thrombus formation) similar to that of spontaneous echocardiographic contrast. These findings may be helpful for early detection of complications leading to secondary surgery or to document the healing process. ${ }^{9}$ Using electrocardiography (ECG) triggering, malperfusion of coronary arteries due to the obliteration by an intimal flap in diastole during reversed flow from the aorta to the coronary arteries could be visualized (-Fig. 2). ${ }^{33}$ Combined with contrast enhancement, the value of echocardiography is further enhanced. ${ }^{34}$ 


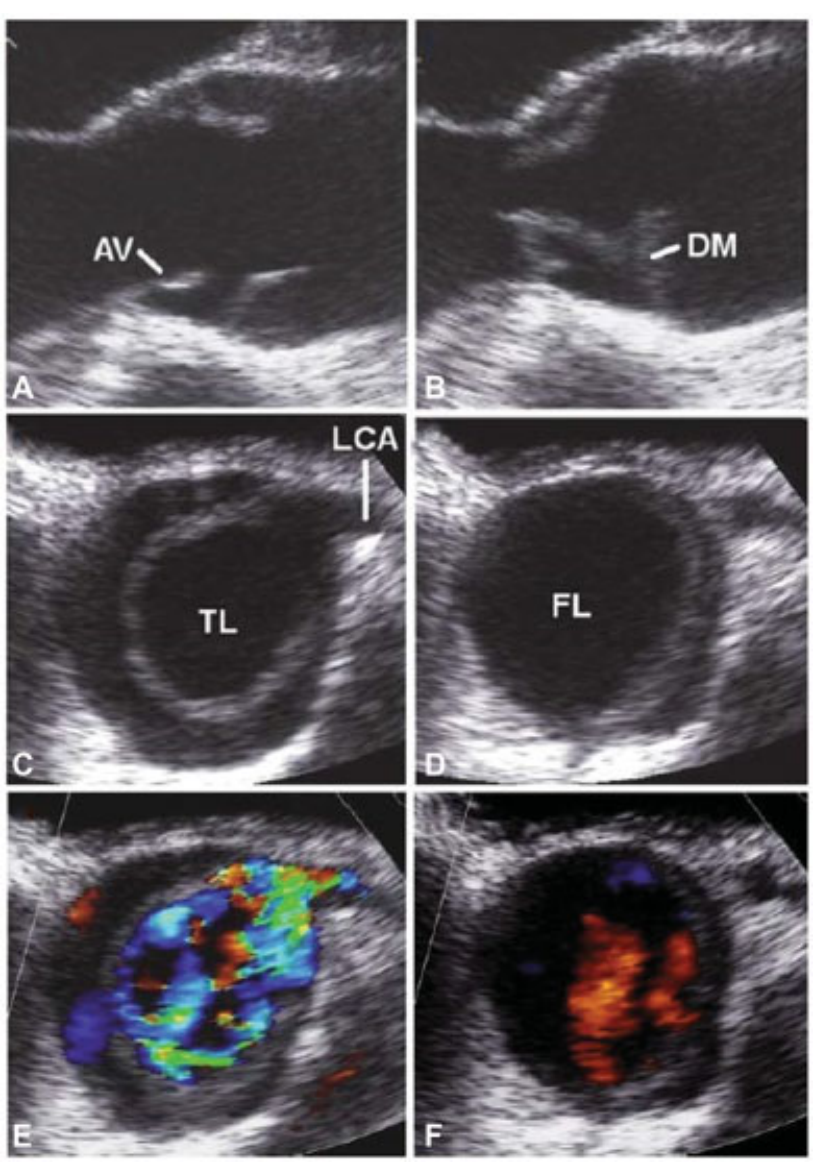

Fig. 2 Intraoperative transesophageal echocardiography. Systolic (A, C, E) and diastolic (B, D, F) movement of the dissection membrane (DM) with prolapse of the DM through the aortic valve (AV). (C-F) Short-axis view of the AV showing the intermittent obstruction of the left coronary ostia (LCA). FL, false lumen; TL, true lumen. Image courtesy: Jánosi at al. ${ }^{33}$

\section{Intracardiac Echocardiography}

A study including 23 Type-B AAD patients compared the diagnostic performance of intracardiac echocardiography (ICE; intraluminal phased-array imaging [IPAI]), TEE, angiography, and IVUS. ${ }^{17}$ IPAI was superior to TEE in detecting entries in the thoracic descending aorta. Furthermore, ICE correctly depicted the abdominal branches and their origins similarly to IVUS but on top of that, it was capable of showing flow in the abdominal side branches, thus proving that they were functionally not impaired. Notably, in patients with TL collapse, this technology allowed guidance of emergency fenestration. ${ }^{17}$

\section{Intravascular Ultrasound}

IVUS provides real-time imaging of aortic pathology and is a reliable and safe tool to guide stent-graft positioning. Since its first application in the 1990s in a patient with $\mathrm{AAD},{ }^{18}$ IVUS imaging has been used as an enhanced technique for diagnostic and therapeutic procedures in patients with AAD. Weintraub and colleagues ${ }^{18}$ validated the diagnostic performance of this technology in 23 patients with $\mathrm{AAD}$, as compared with aortography, $\mathrm{CT}$, and TEE. In all patients, IVUS was able to detect the intimal flap, TL and FL, involvement of branch vessels, presence of IMH, and thrombus formation. Notably, IVUS was superior to aortography, CT, and TEE in demonstrating the distal extent of dissection in ambiguous cases. In contrast, TEE depicted more clearly the dissection in the ascending aorta, potential multiple communications between TL and FL, and impaired flow in the coronary arteries. ${ }^{17}$ In comparison to MRI, IVUS images demonstrated a surprising good agreement even for detection of PAU. ${ }^{35}$ Furthermore, IVUS enabled real-time aortic diameter assessment and may be therefore useful in guiding stent-graft size. In a study involving 45 Type-B AAD patients, IVUS-assisted sizing yielded a greater increase in TL and reduction of FL and total aortic diameter during follow-up, compared with CT-assisted sizing (-Supplementary Fig. S2; available in the online version). ${ }^{19}$ Although IVUS cannot be recommended routinely due to its cost inefficiency, it should be taken into account as a resourceful tool when CT image quality is poor and, in patients, with hemodynamic compromise. In this setting, poor volume filling at the time of CT may lead to underestimation of aortic diameter. In contrast, IVUS enables the measurement of the exact diameter quite before thoracic endovascular aortic repair (TEVAR) after stabilization of the patient with volume filling and reduces the incidence of stent-graft oversizing. $^{20,36}$

However, pitfalls of IVUS are to be remembered. If the common IVUS catheter with rotating transducers is used, flow information is lacking, as Doppler is not possible. The catheter tip follows the direction of the guidewire.

The dedicated ICE catheters are opening another view, because the aorta can be imaged from the superior and inferior cava, but also from the heart, right ventricle. ${ }^{37}$ The full flexibility of the catheter tip in three dimensions is a great advantage. In addition, the ICE catheter can be moved within the aorta which is helpful to image the entry tears or ostium of the side branches. Meanwhile, IVUS had been used to guide interventions. In the no-reflow situation, fenestration had been the only approach which could be used in the cath laboratory. ${ }^{38,39}$ Now, in the era of TEVAR/endovascular aneurysm repair (EVAR), the indication for a fenestration is rare but an excellent solution when a no reflow persists after stenting. Particularly for biopsy of a mass of unknown etiology within the lumen of the aorta, the support of imaging is extremely helpful. ${ }^{40}$

Although the correlation between aortic diameters at CT and IVUS was overall good along the aorta (especially abdominal aorta), IVUS tended to overestimate luminal diameter due the tortuosity of the aortic arch and the drift out of the coaxial axis. The greatest difference in diameter measurements was observed at the origin of the left subclavian artery (IVUS - CT $=2.69 \pm 2.03 \mathrm{~mm}$ ), a common proximal landing zone in TEVAR (-Supplementary Fig. S2; available in the online version). ${ }^{19}$

Therefore, one possible strategy for stent-graft selection is to use only the minimum measured diameter when you are aware of an off-center measurement of IVUS. ${ }^{19}$

IVUS is very helpful for the surgeon when problems exist related to the abdominal and thoracic aorta, because the passage of guidewires and catheters can be guided.

\section{Computed Tomography}

Given the excellent accuracy, the short-time image acquisition/ processing, widespread availability, and patient tolerance, $\mathrm{CT}$ is 
considered to be the ideal diagnostic tool in emergency scenarios. ${ }^{1}$ Furthermore, it enables a complete and detailed map of the entire aorta and its branches with high spatial/contrast resolution without limiting for image window. In the beginning, only single-row detectors were available but nowadays, dual source scanners, and up to 624-scan lines are present. The resolution increased significantly combined with rapid data acquisition. Nonenhanced CT followed by contrastenhanced CT should be preferred to assess patients with suspected AAS. However, ECG gating is recommended to avoid artifacts. The main limitations are related to lack of aortic regurgitation detection (often present in Type-A AAD) and lack of measurement of flow and flow direction. Furthermore, the impossibility to be performed at bedside limits its feasibility in unstable patients. CT disadvantages consist in the increased risk of allergic reactions due to the use of iodinated contrast agents and iodinated contrast medium. Cumulative exposure to radiation remains a major drawback (especially in young patients) during surveillance where serial CT scans are needed.

Rylski et $\mathrm{al}^{22}$ investigated changes in descending aortic geometry due to dissection among 25 Type-B AAD patients. All the patients underwent CT less than 2 years before AAD and immediately after. The largest increase in postdissection diameter was registered at the level of the middescending thoracic aorta $(+6.4 \mathrm{~mm} ;+23 \%)$. In addition, an increase in length and volume of the descending thoracic aorta was noted. Interestingly, the investigators found that the predissection aortic diameter appears to be the most similar to the postdissection maximum diameter of the $\mathrm{TL}(+2.5 \mathrm{~mm})$.

\section{Magnetic Resonance Imaging}

The value of MRI in aortic disease was a main topic of the study by Nienaber et $\mathrm{al}^{41,42}$ in Hamburg taking into account that MRI has limited value in the acute setting but great advantages in the chronic phase. In addition, different types of aortic disease were visualized similar to TEE scans but for the whole aorta. Very early, the Mainz group pointed to the diagnostic value of MRI in aortic disease. ${ }^{43}$ The main emphasis was found in the differential diagnosis of aortic disease. IMH attracted the interest, as it became clear that this type of aorta pathology quite often leads to full aortic dissection and is often found when aortic dissection was suggested, with the advantage of imaging the whole aorta and not only the thoracic part with high resolution. ${ }^{44,45}$ However, IMH had been described by pathologists quite early $^{46,47}$ as aortic dissection, without intimal rupture, diagnosed with MRI and CT. ${ }^{48}$ Nevertheless, problems exist for the detection and localization of calcification and metal stents. The ability to detect flow in TL and FL, to detect the perfusion direction and the degree of flow are very important, as well as the optimal spatial orientation. Therefore, the first attempts were done in Essen by Eggebrecht et $\mathrm{al}^{49}$ to use MRI for stent implantation (- Supplementary Fig. S3; available in the online version). Further refinement of real-time MRI will provide an option for enhanced stent graft implantation in the future.

\section{Positron Emission Tomography/Computed Tomography}

${ }^{18} \mathrm{~F}$-FDG PET/CT is an imaging technique that provides morphological and metabolic information by detecting increased
FDG uptake. Provided the proven role of this imaging modality in the field of oncology and patients with vasculitis, PET/CT imaging may play also an important prognostic role in patients with AAS. In 60 patients with Type-B AAS, a pathological FDG uptake in the aortic wall was associated with a significant increase in inflammatory biomarkers (i.e., C-reactive protein and D-dimer). Although PET positivity did not affect in-hospital outcome, during follow-up, PET-positive patients had a greater risk of disease progression, aortarelated mortality, and reintervention than PET-negative patients. Interestingly, the combination of PET results with D-dimer levels had the best discriminant value of major adverse events, compared with PET, D-dimer, and C-reactive protein taken individually (-Supplementary Fig. S4; available in the online version). ${ }^{24}$ Thus, this combined strategy (metabolic and biochemical information) may prove to be helpful in more accurately identifying patients with multiple risk factors (amount of thrombus, active FL, inflammation in the aortic wall, intimal tears, etc.) who are at higher risk for disease progression and complications during follow-up. Similarly, evidence of a PET-positive aortic pathology may justify a closer follow-up or a more aggressive treatment with surgery/endovascular therapy in medically treated AAD patients to improve the outcomes. ${ }^{23,24}$

\section{Role of Biomarkers in Acute Aortic Syndromes}

As in other cardiovascular diseases, biomarkers represent an important part of the comprehensive assessment of patients with suspected or overt AAS (-Table 6). Key pioneer studies undertaken by Mainz-Essen investigators have shed the light on the diagnostic and prognostic role of biomarkers.

\section{D-Dimer as a Diagnostic Marker of Acute Aortic Dissection}

In 2004, a multicenter study involving 64 chest pain patients showed that D-dimer was highly elevated in those with AAD, with similar levels to pulmonary embolism and significantly higher than those with acute myocardial infarction, chronic aortic dissection, and other causes of noncardiac chest pain (-Fig. 3). ${ }^{25}$ Additionally, a systemic inflammatory response including significant increase of white blood cells, C-reactive protein, and fibrinogen was evident in AAD patients. ${ }^{25,26}$ These results were furtherly validated in 2017 with a single-center study involving 522 patients, 231 of them suffering from AAS (159 AAD, 35 $\mathrm{IMH}$, and $37 \mathrm{PAU}){ }^{27}$ Among AAS patients, those with AAD and $\mathrm{IMH}$ had comparably increased D-dimer levels, as compared with patients with pulmonary embolism, myocardial infarction, and other causes of chest pain, whereas this was not the case of PAU patients. Similarly, the discriminant value of D-dimer was excellent both for AAD and IMH (area under the curve $[A U C]=0.96$, sensitivity $=99 \%$, and specificity $=67 \%$; and $A U C=0.98$, sensitivity $=100 \%$, and specificity $=67 \%$, respectively) but not for PAU (AUC $=0.69$, sensitivity $=64 \%$, and specificity $=67 \%) .{ }^{27}$ 
Table 6 Laboratory tests required for patients with acute aortic syndromes

\begin{tabular}{|l|l|}
\hline Laboratory tests & To detect signs of: \\
\hline Red blood cell count/hemoglobin & Blood loss, bleeding, anemia \\
\hline White blood cell count & Infection, inflammation (systemic inflammatory response syndrome [SIRS]) \\
\hline C-reactive protein & Inflammatory response \\
\hline Interleukin-6 & Vascular inflammation \\
\hline Procalcitonin & Differential diagnosis between SIRS and sepsis \\
\hline Creatine kinase & Reperfusion injury, rhabdomyolysis \\
\hline Troponin I or T & Myocardial ischemia, myocardial infarction \\
\hline D-dimer & Aortic dissection, pulmonary embolism, thrombosis \\
\hline Creatinine & Renal failure (existing or developing) \\
\hline $\begin{array}{l}\text { Alanine aminotransferase/ } \\
\text { aspartate transaminase }\end{array}$ & Liver ischemia, liver disease \\
\hline Lactate & Bowel ischemia, metabolic disorder \\
\hline Glucose & Diabetes mellitus \\
\hline Blood gases & Metabolic disorder, oxygenation \\
\hline $\begin{array}{l}\text { Brain natriuretic peptide/ } \\
\text { N-terminal probrain natriuretic peptide }\end{array}$ & Heart failure \\
\hline
\end{tabular}

Note: Modified from Erbel et al. ${ }^{1}$

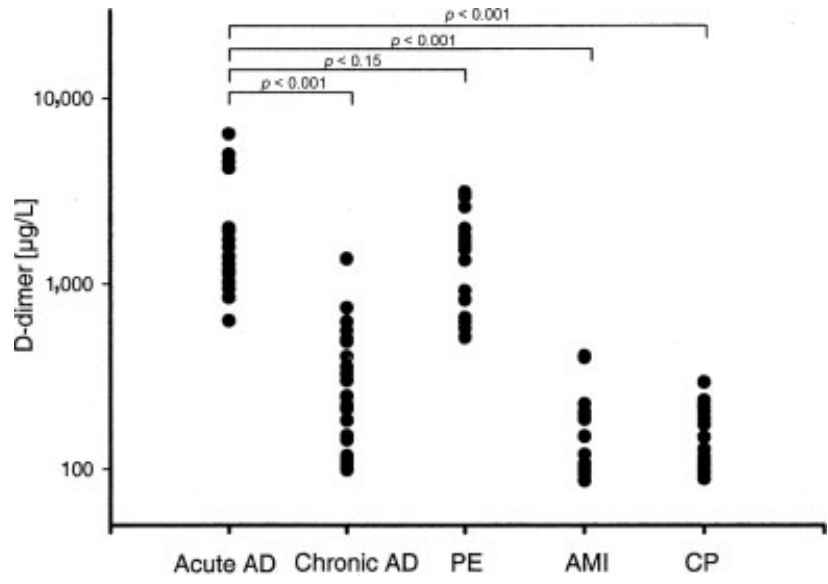

Fig. 3 Comparison of D-dimer values between the different patient groups ( $p$-values adjusted according to Bonferroni correction). AD, aortic dissection; $\mathrm{AMI}$, acute myocardial infarction; $\mathrm{CP}$, chest pain; $\mathrm{PE}$, pulmonary embolism. Image courtesy: Eggebrecht et al. ${ }^{25}$

\section{Integrated Clinical Biomarkers and Imaging Diagnostic Algorithm}

In 2010, the American and ACC/AHA guidelines for the diagnosis and management of patients with thoracic aortic disease designed an initial a priori risk estimate based on predisposing conditions, pain features and clinical examination to identify patients at low (score: $0-1$ ) and high (score: $2-3$ ) risk for AAD (-Supplementary Fig. S5A; available in the online version). ${ }^{9}$ The proposed risk estimate tested among 2,538 patients enrolled in International Registry of Acute Aortic Dissection (IRAD) registry showed an excellent diagnostic sensitivity (95.7\%). ${ }^{50}$ Subsequently, the 2014 European Society of Cardiology (ESC) guidelines ${ }^{1}$ on the diagnosis and treatment of aortic diseases integrated the pretest probability estimation with laboratory (D-dimer) and imaging tests (echocardiography and/or CT) to rapidly confirm or rule out the diagnosis of aortic dissection (-Supplementary Fig. S5B; available in the online version). ${ }^{1}$ Validation into the real-world management of patients with suspected AAD of the ESC guidelines integrated diagnostic algorithm was performed among 376 chest pain patients, 85 of them with AAS. ${ }^{28}$

A "high probability" aortic dissection detection (ADD) score (2 or 3 ) detected AAS with good specificity (98.9\%) with a failure rate of $9.7 \%$. A "low probability" ADD score (0 or 1 ) combined with negative D-dimer $(<0.5 \mathrm{ng} / \mathrm{L})$ safely and efficiently ruled out AAS with a negative predictive value of $98.9 \%$ and a low failure rate (1.1\%). ${ }^{28}$ These findings were confirmed also by another group in a prospective multicenter study. ${ }^{51}$ Therefore, whereas in patients with "high probability," ADD risk score D-dimer assessment is not necessary and expedite aortic imaging (CT or TEE) should be warranted to confirm AAD, it plays a pivotal role when assessed in individuals with a "low probability" ADD risk score. First, a negative $\mathrm{D}$-dimer rules out $\mathrm{AAD}$, owing to the excellent negative predictive value; and second, a positive $\mathrm{D}$-dimer warrants further aortic imaging which may lead to the detection of AAS in patients with an atypical presentation that would remain undetected on the basis of the ADD risk score alone. However, it has to be underlined that D-dimer may result within normal limits in the case of AAD with thrombosed FL, IMH, and PAU.

\section{Hemoglobin}

Gorla et $\mathrm{al}^{30}$ investigated among 144 Type-B AAS undergoing TEVAR, the prognostic impact of preoperative anemia and postoperative hemoglobin (Hb) drop on in-hospital mortality, and the incidence of acute kidney injury (AKI). Three groups of patients were identified (no/mild, moderate, and severe) 
based on values of preoperative anemia and postoperative $\mathrm{Hb}$ drop. Data showed that postoperative AKI was higher in the severe and moderate anemia groups than in the no/mild anemia group and that in-hospital mortality and AKI were higher in patients with severe postoperative $\mathrm{Hb}$ drop than in patients with moderate or mild postoperative Hb drop. ${ }^{30}$

Therefore, preoperative anemia and postoperative $\mathrm{Hb}$ drop appear to predict in-hospital mortality and to be significant risk factors for AKI. ${ }^{30}$

\section{Conclusion}

The unique 35-year-long Mainz-Essen experience represents a milestone of the aortic disease research journey. New horizons have been opened on biomarker-imaging interplay to provide timely diagnosis, assessment of prognosis, and guidance for therapeutic interventions. In this regard, the development and subsequent validation of 2014 ESC guidelines on the diagnosis and treatment of aortic diseases diagnostic algorithm represents a milestone on the evaluation of patients with suspected AAS in the emergency scenario. However, more should be done to investigate potential serological and imaging biomarkers signaling clinically silent cases of early anatomopathological changes of the aortic wall to implement optimal preventive measures. On the other hand, there is a need to prevent redissection or aneurysm formation after optimal interventions of the acute index event. Thus, the primary and secondary aortic disease prevention landscape remains to be explored in the coming years. In this scenario, genetics, proteomics, biomarkers, and advances in imaging may play a major role in an integrated multiparametric approach.

\section{Funding}

None.

\section{Conflict of Interest}

The authors declare no conflict of interest related to this article.

\section{Acknowledgment}

None.

\section{References}

1 Erbel R, Aboyans V, Boileau C, et al; ESC Committee for Practice Guidelines The Task Force for the Diagnosis and Treatment of Aortic Diseases of the European Society of Cardiology (ESC) 2014 ESC Guidelines on the diagnosis and treatment of aortic diseases: Document covering acute and chronic aortic diseases of the thoracic and abdominal aorta of the adult. Eur Heart J 2014;35 (41):2873-2926

2 DeMartino RR, Sen I, Huang Y, et al. Population-based assessment of the incidence of aortic dissection, intramural hematoma and penetrating ulcer, and its associated mortality from 1995 to 2015. Circ Cardiovasc Qual Outcomes 2018;11(08):e004689

3 Howard DP, Banerjee A, Fairhead JF, Perkins J, Silver LE, Rothwell PMOxford Vascular Study. Population-based study of incidence and outcome of acute aortic dissection and premorbid risk factor control: 10-year results from the Oxford Vascular Study. Circulation 2013;127(20):2031-2037

4 Clouse WD, Hallett JW Jr., Schaff HV, et al. Acute aortic dissection: population-based incidence compared with degenerative aortic aneurysm rupture. Mayo Clin Proc 2004;79(02):176-180

5 Evangelista A, Isselbacher EM, Bossone E, et al; IRAD Investigators. Insights from the International Registry of Acute Aortic Dissection: a 20-year experience of collaborative clinical research. Circulation 2018;137(17):1846-1860

6 Jánosi RA, Gorla R, Tsagakis K, et al. Thoracic endovascular repair of complicated penetrating aortic ulcer: an 11-year single-center experience. J Endovasc Ther 2016;23(01):150-159

7 Nienaber CA, Clough RE. Management of acute aortic dissection. Lancet 2015;385(9970):800-811

8 Bossone E, LaBounty TM, Eagle KA. Acute aortic syndromes: diagnosis and management, an update. Eur Heart J 2018;39 (09):739-749d

9 Hiratzka LF, Bakris GL, Beckman JA, et al; American College of Cardiology Foundation/American Heart Association Task Force on Practice Guidelines American Association for Thoracic Surgery American College of Radiology American Stroke Association Society of Cardiovascular Anesthesiologists Society for Cardiovascular Angiography and Interventions Society of Interventional Radiology Society of Thoracic Surgeons Society for Vascular Medicine. 2010 ACCF/AHA/AATS/ACR/ASA/SCA/SCAI/SIR/STS/ SVM guidelines for the diagnosis and management of patients with Thoracic Aortic Disease: a report of the American College of Cardiology Foundation/American Heart Association Task Force on Practice Guidelines, American Association for Thoracic Surgery, American College of Radiology, American Stroke Association, Society of Cardiovascular Anesthesiologists, Society for Cardiovascular Angiography and Interventions, Society of Interventional Radiology, Society of Thoracic Surgeons, and Society for Vascular Medicine. Circulation 2010;121(13):e266-e369

10 Börner N, Erbel R, Braun B, Henkel B, Meyer J, Rumpelt J. Diagnosis of aortic dissection by transesophageal echocardiography. Am J Cardiol 1984;54(08):1157-1158

11 Erbel R, Börner N, Steller D, et al. Detection of aortic dissection by transoesophageal echocardiography. Br Heart J 1987;58(01): 45-51

12 Erbel R, Engberding R, Daniel W, Roelandt J, Visser C, Rennollet H. Echocardiography in diagnosis of aortic dissection. Lancet 1989;1 (8636):457-461

13 Mohr-Kahaly S, Erbel R, Rennollet H, et al. Ambulatory follow-up of aortic dissection by transesophageal two-dimensional and colorcoded Doppler echocardiography. Circulation 1989;80(01):24-33

14 Erbel R, Oelert H, Meyer J, et al; The European Cooperative Study Group on Echocardiography. Effect of medical and surgical therapy on aortic dissection evaluated by transesophageal echocardiography. Implications for prognosis and therapy. Circulation 1993;87(05):1604-1615

15 Mohr-Kahaly S, Erbel R, Kearney P, Puth M, Meyer J. Aortic intramural hemorrhage visualized by transesophageal echocardiography: findings and prognostic implications. J Am Coll Cardiol 1994;23(03):658-664

16 Epperlein S, Mohr-Kahaly S, Erbel R, Kearney P, Meyer J. Aorta and aortic valve morphologies predisposing to aortic dissection. An in vivo assessment with transoesophageal echocardiography. Eur Heart J 1994;15(11):1520-1527

17 Bartel T, Eggebrecht H, Müller S, et al. Comparison of diagnostic and therapeutic value of transesophageal echocardiography, intravascular ultrasonic imaging, and intraluminal phased-array imaging in aortic dissection with tear in the descending thoracic aorta (type B). Am J Cardiol 2007;99(02):270-274

18 Weintraub AR, Erbel R, Görge G, et al. Intravascular ultrasound imaging in acute aortic dissection. J Am Coll Cardiol 1994;24(02): 495-503 
19 Jánosi RA, Gorla R, Rogmann K, et al. Validation of intravascular ultrasound for measurement of aortic diameters: Comparison with multi-detector computed tomography. Minim Invasive Ther Allied Technol 2015;24(05):289-295

20 Lortz J, Tsagakis K, Rammos C, et al. Intravascular ultrasound assisted sizing in thoracic endovascular aortic repair improves aortic remodeling in Type B aortic dissection. PLoS One 2018;13 (04):e0196180

21 Lortz J, Tsagakis K, Rammos C, et al. Hemodynamic changes lead to alterations in aortic diameters and may challenge further stent graft sizing in acute aortic syndrome. J Thorac Dis 2018;10(06): 3482-3489

22 Rylski B, Muñoz C, Beyersdorf F, et al. How does descending aorta geometry change when it dissects? Eur J Cardiothorac Surg 2018; 53(04):815-821

23 Kuehl H, Eggebrecht H, Boes T, et al. Detection of inflammation in patients with acute aortic syndrome: comparison of FDG-PET/CT imaging and serological markers of inflammation. Heart 2008;94 (11):1472-1477

24 Gorla R, Erbel R, Kuehl H, et al. Prognostic value of (18)Ffluorodeoxyglucose PET-CT imaging in acute aortic syndromes: comparison with serological biomarkers of inflammation. Int J Cardiovasc Imaging 2015;31(08):1677-1685

25 Eggebrecht H, Naber CK, Bruch C, et al. Value of plasma fibrin Ddimers for detection of acute aortic dissection. J Am Coll Cardiol 2004;44(04):804-809

26 Eggebrecht H, Mehta RH, Metozounve H, et al. Clinical implications of systemic inflammatory response syndrome following thoracic aortic stent-graft placement. J Endovasc Ther 2008;15 (02):135-143

27 Gorla R, Erbel R, Kahlert P, et al. Diagnostic role and prognostic implications of D-dimer in different classes of acute aortic syndromes. Eur Heart J Acute Cardiovasc Care 2017;6(05): 379-388

28 Gorla R, Erbel R, Kahlert P, et al. Accuracy of a diagnostic strategy combining aortic dissection detection risk score and D-dimer levels in patients with suspected acute aortic syndrome. Eur Heart J Acute Cardiovasc Care 2017;6(05):371-378

29 Gorla R, Erbel R, Kahlert P, et al. Clinical features and prognostic value of stent-graft-induced post-implantation syndrome after thoracic endovascular aortic repair in patients with type B acute aortic syndromes. Eur J Cardiothorac Surg 2016;49(04): 1239-1247

30 Gorla R, Tsagakis K, Horacek M, et al. Impact of preoperative anemia and postoperative hemoglobin drop on the incidence of acute kidney injury and in-hospital mortality in patients with type $B$ acute aortic syndromes undergoing thoracic endovascular aortic repair. Vasc Endovascular Surg 2017;51(03):131-138

31 Erbel R. Transesophageal echocardiography. New window to coronary arteries and coronary blood flow. Circulation 1991;83 (01):339-341

32 Erbel R. Role of transesophageal echocardiography in dissection of the aorta and evaluation of degenerative aortic disease. Cardiol Clin 1993;11(03):461-473

33 Jánosi RA, Buck T, Erbel R. Mechanism of coronary malperfusion due to type-a aortic dissection. Herz 2009;34(06):478

\section{Editor's Commentary}

These two articles, Part I (published here) and Part II (to be published in the next issue of AORTA), summarize clearly the advances in thoracic aortic disease-imaging, diagnosis, and treatment-made over the last several decades. Many of
34 Jánosi RA, Erbel R. A better echocardiographic view to aortic dissection. Eur Heart J 2010;31(04):398-400

35 Erbel R. Diseases of the thoracic aorta. Heart 2001;86(02): 227-234

36 Lortz J, Papathanasiou M, Rammos C, et al. High intimal flap mobility assessed by intravascular ultrasound is associated with better short-term results after TEVAR in chronic aortic dissection. Sci Rep 2019;9(01):7267

37 Bartel T, Konorza T, Arjumand J, et al. Intracardiac echocardiography is superior to conventional monitoring for guiding device closure of interatrial communications. Circulation 2003;107(06): 795-797

38 Görge G, Ge J, Haude $\mathrm{M}$, et al. Intravascular ultrasound for evaluation of coronary arteries. Herz 1996;21(02):78-89

39 Eggebrecht $\mathrm{H}$, Baumgart D, Herold U, et al. Interventional management of aortic dissection. Herz 2002;27(06):539-547

40 Bartel T, Eggebrecht H, Erbel R. Safe biopsy of aortic masses guided by intraluminal two dimensional ultrasonography. Heart 2004;90 (09):974

41 Nienaber CA, Spielmann RP, von Kodolitsch Y, et al. Diagnosis of thoracic aortic dissection. Magnetic resonance imaging versus transesophageal echocardiography. Circulation 1992;85(02): 434-447

42 Nienaber CA, von Kodolitsch Y, Nicolas V, et al. The diagnosis of thoracic aortic dissection by noninvasive imaging procedures. $\mathrm{N}$ Engl J Med 1993;328(01):1-9

43 Just M, Mohr-Kahaly S, Kreitner KF, et al. [Magnetic resonance tomography of chronic aortic dissection] (in German). RoFo Fortschr Geb Rontgenstr Nuklearmed 1993;158(02):109-114

44 Nienaber CA, von Kodolitsch Y, Petersen B, et al. Intramural hemorrhage of the thoracic aorta. Diagnostic and therapeutic implications. Circulation 1995;92(06):1465-1472

45 Kodolitsch Y, Spielmann RP, Petersen B, et al. [Intramural hemorrhage of the thoracic aorta as a precursor of dissection] (in German). Z Kardiol 1995;84(11):939-946

46 Krukenberg E. Beitrage zu frage des aneurysma dissecans. Beitr Pathol Anat Allg Pathol 1920;67:329-351

47 Gore I. Pathogenesis of dissecting aneurysm of the aorta. AMA Arch Pathol 1952;53(02):142-153

48 Yamada T, Tada S, Harada J. Aortic dissection without intimal rupture: diagnosis with MR imaging and CT. Radiology 1988;168 (02):347-352

49 Eggebrecht H, Kühl H, Kaiser GM, et al. Feasibility of real-time magnetic resonance-guided stent-graft placement in a swine model of descending aortic dissection. Eur Heart J 2006;27(05): 613-620

50 Rogers AM, Hermann LK, Booher AM, et al; IRAD Investigators. Sensitivity of the aortic dissection detection risk score, a novel guideline-based tool for identification of acute aortic dissection at initial presentation: results from the international registry of acute aortic dissection. Circulation 2011;123(20):2213-2218

51 Nazerian P, Mueller C, Soeiro AM, et al; ADvISED Investigators. ADvISED Investigators. diagnostic accuracy of the aortic dissection detection risk score plus D-dimer for acute aortic syndromes: the ADvISED prospective multicenter study. Circulation 2018;137 (03):250-258

these advances were originated by the Essen team, who authored these articles. I hope our readers find the narratives and the tabulations of relevant key articles extremely useful as historical, clinical, and didactic tools. These articles are reflective of great concentration, innovation, and creativity in treatment of aortic diseases. 